\title{
Designing Mobile Interactions for the Ageing Populations
}

\begin{abstract}
Sayan Sarcar*
Kochi University of Technology

Kochi, Japan

sayan.sarcar@kochi-tech.ac.jp

Cosmin Munteanu

University of Toronto

Mississauga, Canada

cosmin.munteanu@utoronto.ca
\end{abstract}

Jussi P. P. Jokinen

Aalto University, Finland

jussi.jokinen@aalto.fi

\section{Antti Oulasvirta}

Aalto University, Finland

antti.oulasvirta@aalto.fi

* Contact authors

Permission to make digital or hard copies of part or all of this work for personal or classroom use is granted without fee provided that copies are not made or distributed for profit or commercial advantage and that copies bear this notice and the full citation on the first page. Copyrights for third-party components of this work must be honored. For all other uses, contact the Owner/Author.

Copyright is held by the owner/author(s).

CHI'17 Extended Abstracts, May 06-11, 2017, Denver, CO, USA

Chaklam Silpasuwanchai

Kochi University of Technology

Kochi, Japan

chaklam@kochi-tech.ac.jp

\section{Neil Charness}

Florida State University

Florida, USA

charness@psy.fsu.edu

\section{Mark Dunlop}

Strathclyde University, UK

mark.dunlop@strath.ac.uk

\section{Xiangshi Ren*}

Kochi University of Technology

Kochi, Japan

ren.xiangshi@kochi-tech.ac.jp

(1)


years old are expected to comprise $27 \%$ and $15 \%$ of these nations' population, respectively, by $2050[4,6]$. Although issues related to older adults are receiving substantial attention in other areas of research e.g., Gerontology, Accessibility, Cognitive Psychology, the $\mathrm{HCI}$ community might contribute more.

Ageing is associated with a multitude of biological, cognitive, and social changes that impact the use of technology [5]. In particular, in case of mobile devices, these can seriously hamper usability. However, age also brings new opportunities, which well-designed mobile apps could support, such as increased spare time, strengthened family connections, and new learning and travel opportunities.

The digital revolution has not adequately considered the needs of the ageing populations. Although older adults constitute an increasing segment of the demographics, the majority of research on $\mathrm{HCI}$, as well as industrial companies, focuses almost exclusively on younger adults. As a result, even though smartphone ownership among older adults has significantly increased in recent years $[2,3,12]$, smartphone adoption level for is still low (e.g., smartphone ownership in the US is at $27 \%$ for older adults as of 2015 , whereas $85 \%$ of young people aged $18-29$ are smartphone owners [13]). Consequently, older adults may be losing the possible benefits and opportunities from this growing digital era $[1,5,7]$.

The main goal of this workshop is to discuss suitable design and evaluation strategies of Mobile UIs as well as to coordinate efforts and raise awareness of HCI as it affects older adults and to rethink designing and evaluating mobile interfaces for this community.

\section{Workshop Goals}

$\mathrm{CHI}$ is one of the most multidisciplinary research communities. In recent years it has made tremendous progress in supporting many marginalized user groups (e.g. low literacy, developing countries, accessibility) or in addressing critical societal needs (e.g. sustainability, inclusion). These have been enabled by advancement in research and design, such as new interaction paradigms or novel devices. We believe it is now timely to more systemically investigate how, as a community, we can leverage such advances and better support the safety, health, social, or digital inclusion needs of older adults. While recent years have seen an increase in such research activity at $\mathrm{CHI}$, it has mostly materialized in the form of isolated publications. Yet there is increasingly strong evidence that $\mathrm{HCI}$ researchers are increasingly interested in this topic. This is exemplified by the very large attendance (more than 50

participants) to our first Special Interest Group (SIG) on Older Adults, at CHI 2016 [10], or by the numerous submissions received by recent workshops such as Reimagining commonly used mobile interfaces for older adults in MobileHCI 2014 [15], and 2nd Workshop on Designing with Older Adults: Towards a Complete Methodology in MobileHCI 2015 [16] or the first-ever international symposium on Interactive Technology and Ageing Populations [17], held in October 2016. All these recent events were co-organized by the proponents of this workshop submission.

Capitalizing on this recent increase in interest, this workshop aims to reach three goals as follows:

\section{Building a Research Repository}

Presently researchers working on this topic are scattered across different fields. The research outcomes, experiences, and practices are not 
disseminated across the boundaries of these fields. Thus, a major goal of this workshop is to bring researchers from these fields together to synthesize and collate findings from different disciplines, and create opportunities to explore bridging between several field experts in order to develop efficient, effective, usable, and adoptive mobile technologies and more appropriate methods.

\section{Community Building}

Senior-centred research and development is currently conducted in academic and industry research labs in a rather disjoint manner. As such, this workshop's goal is to link the SIGCHI community with researchers and practitioners across academic disciplines (such as the Gerontology, Cognitive Science, Psychology, Cognitive Neuroscience) and industries who are actively working or having interest toward understanding older adults' technology use, specifically mobile applications. For future collaborations, mailing lists and post-CHI activities (e.g., a symposia/summer school) will be established.

\section{Raising Awareness}

Interactive technologies for seniors is a significant market of interest for industries, expected to grow from US\$ 2 billion to an estimated US\$30 billion in the next few years [8]. This is a natural reflection of the size of this user group (16\% of population [9]). Yet interest in $\mathrm{HCI}$ is still relatively small (less than $1 \%$ of all $\mathrm{CHI}$ 2015 accepted submissions across all tracks can be categorized as focused on older adults). This workshop aims to raise awareness of the challenges and research opportunities in this field.

\section{Workshops Themes}

As the proposed inaugural CHI workshop on Designing Mobile Interactions for the Ageing Populations, we are suggesting several relevant themes for guiding the participants' position papers and discussions during the workshop.

\section{Current Issues}

This topic will focus on discussing issues related to human factors, perception, memory, and motor movement of older adults, and how these issues affect senior-based mobile interface design.

\section{Models and Design}

This topic will focus on discussing the state-of-the-art models and design principles for mobile interfaces of older adults. For example, as current mobile interfaces tend to follow a "one design for all" approach, the model parameters can be further tuned to cover individual differences among aged people and abilitybased design and optimization principles can be implemented to find the effective senior-based mobile interface design [14].

\section{Evaluation Methodologies}

Evaluating senior-based user interfaces still face many challenges, particularly in accurately understanding the preferences, habits, and adoption challenges of older adults [16]. This topic will focus on discussing the state-of-the-art evaluation methods, to discuss how suitable is the current methods to judge the efficacy of the mobile interface design, and identify future research opportunities.

\section{Applications}

This topic will discuss what some potentially useful applications for older adults are. For examples, textentry methods can enhance the usability of messaging 
applications. Games and social applications [11] have the potential to improve the wellbeing of older adults.

\section{References}

1. Farah Arab, Yasir Malik, and Bessam Abdulrazak. 2013. Evaluation of phonage: an adapted smartphone interface for elderly. In Proc. INTERACT, 547-554. http://dx.doi.org/10.1007/978-3-642-40498-6_44

2. ComScore 2012. Mobile future in focus, 2012, Retrieved 16 January 2015 from

https://www.comscore.com/Insights/PressReleases/2012/2/comScore-Releases-the-2012Mobile-Future-in-Focus-Report.

3. Deloitte. The smartphone generation gap: over-55? There's no app for that, 2014.

https://www2.deloitte.com/au/en/pages/technologymedia-and-

telecommunications/articles/2014predictions-thesmartphone-generation-gap.html.

4. Miranda A Farage, Kenneth W Miller, Funmi Ajayi, and Deborah Hutchins. Design principles to accommodate older adults. Global journal of health science. 4, 2 (March 2012).

5. Arthur D Fisk, Wendy A. Rogers, Neil Charness, Sara J. Czaja, and Joseph Sharit. 2012. Designing for older adults: Principles and creative human factors approaches. CRC press, FL, USA.

6. Query $9 / 22 / 15$ to

http://www.census.gov/population/international/data/i $\mathrm{db} /$ region. php? $\mathrm{N}=\% 20$ Results $\% 20 \& \mathrm{~T}=1 \& \mathrm{~A}=$ aggregate $\& R T=0 \& Y=2050 \& R=101,102 \& C=$. Retrieved results 30 September, 2015.

7. Barbara B. Neves, Rachel L. Franz, Cosmin Munteanu, Ronald Baecker, and Mags Ngo. 2015. "My hand doesn't listen to me!": adoption and evaluation of a communication technology for the 'oldest old'. In Proc.

CHI 2015, 1593-1602.
http://dx.doi.org/10.1145/2702123.2702430

8. Laurie M. Orlov. Technology for Aging in Place: 2014 Market Overview. Market Report. Retrieved 31 January 2015 from
http://www.ageinplacetech.com/files/aip/Market Overview 1-20-2014 Combined.pdf

9. Stats Canada Population Estimates, 2014. Retrieved 22 February 2015 from

http://www.statcan.gc.ca/daily-

quotidien/140926/dq140926b-eng.htm.

10. Neil Charness et al. 2016. In Proc. CHI EA '16. ACM, New York, NY, USA, 1131-1134. DOI:

http://dx.doi.org/10.1145/2851581.2886431

11. Marilyn R. McGee-Lennon, Maria K Wolters, and Stephen Brewster. 2011. User-centred multimodal reminders for assistive living. In Proc. CHI 2011, 2105-2114.

http://dx.doi.org/10.1145/1978942.1979248

12. M Anderson. 2015. The demographics of device ownership. Pew Research Center: Washington DC (2015).

13. Aaron Smith. 2015. US smartphone use in 2015. Pew Research Center (2015), 18-29.

14. Sayan Sarcar, Jussi JokInen, Antti Oulasvirta, Chaklam Silpasuwanchai, Zhenxin Wang, and Xiangshi Ren. 2016. Towards Ability-Based Optimization for Aging Users. In Proc. ITAP '16. ACM, New York, NY, USA, 7786. DOI: http://dx.doi.org/10.1145/2996267.2996275

15. Emma Nicol et al. 2014. Re-imagining commonly used mobile interfaces for older adults. In Proc. MobileHCI '14. ACM, New York, NY, USA, 585-588. DOI: http://dx.doi.org/10.1145/2628363.2634261

16. Emma Nicol et al. 2015. 2nd Workshop on Designing with Older Adults: Towards a Complete Methodology. In Proc. MobileHCI '15. ACM, New York, NY, USA, 908911. DOI:

http://dx.doi.org/10.1145/2786567.2795395

17. International Symposium on Interactive Technology and Ageing Populations (IxAP 2016). http://itap2016.xrenlab.com/. 